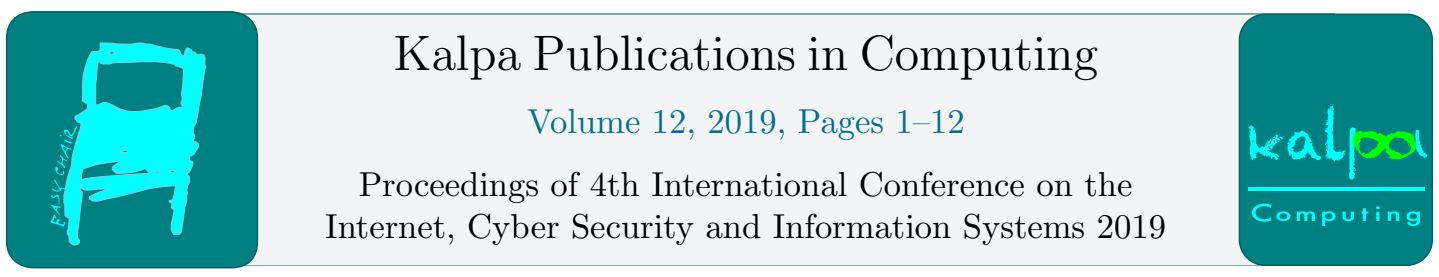

\title{
Artificial Intelligence Affordances for Business Innovation: A Systematic Review of Literature
}

\author{
Luqman Achmat ${ }^{1}$ and Irwin Brown ${ }^{1}$ \\ ${ }^{1}$ Department of Information Systems, University of Cape Town, South Africa \\ luqman.achmategmail.com, irwin.browneuct.ac.za
}

\begin{abstract}
Emerging technologies like artificial intelligence (AI) have begun to play an evermore important role in business innovation. The purpose of this paper is to review current literature to identify definitions and concepts related to artificial intelligence affordances and how artificial intelligence affords business innovation. Using a systematic six-step literature review methodology conducted with an iterative disposition, seven major affordances of AI for business innovation were identified, i.e. (i) Automate business processes, (ii) Customise end user interaction, (iii) Proactively anticipate and react to changes, (iv) Augment and upskill the workforce, (v) Assist decision making, (vi) Improve risk management, and (vii) Develop and enhance intellectual property. The literature surveyed furthermore shows that there are several gaps which allow for further research. Firstly, the definition of artificial intelligence is inconsistent and there is no widely accepted definition. Several AI-based technologies and applications being developed (e.g. Machine Learning, Deep Learning, Natural Language Processing and Neural Networks) require a clear understanding of the affordances of such technologies to be able to make informed strategic decisions. Therefore, understanding the affordances of artificial intelligence in general plays an important role in making such decisions.
\end{abstract}

\section{Introduction}

Business innovation can be defined as a "multi-stage process whereby organizations transform ideas into new/improved products, services or processes, in order to advance, compete and differentiate themselves successfully in their marketplace" (Baregheh, Rowley \& Sambrook, 2009, p. 1334). Several countries are prioritising such innovation ahead of the Fourth Industrial Revolution where emerging technologies such as artificial intelligence (AI), the internet of things (IoT) and blockchain are becoming an increased area of focus in both research and business (Sun, 2018). For example, emerging technologies like the Internet of Things (IoT) play an important role in business innovation, such as efficiently managing the scale and flexibility of supply chain distribution centres (Zhou, 2016; Fujita, 2018), while enabling businesses to maintain a competitive position in the market (Bieringer \& Müller, 
2018). Affordances can be defined as "the possibilities for goal-oriented action afforded to specified user groups by technical objects" (Markus \& Silver, 2008, p. 622). In the case of this paper, the user groups are represented by organisations, the technical objects are represented by the features of AI, the goal-orientated actions are represented by the types of business innovation (e.g. new/improved service or process), and the possibilities are represented as affordances. The topic of affordance has shown popularity in recent studies concerning emerging technologies (Lehrer, Wieneke, vom Brocke, Jung \& Seidel, 2018; Du, Pan, Leidner \& Ying, 2019). It represents the potential actions that may result from the relationship between $\mathrm{AI}$ and the organisation and focuses on business practices as an outcome rather than the properties of the technologies (Fayard \& Weeks, 2014).

AI will ultimately play a pivotal role in every industry worldwide (Plastino \& Purdy, 2018). It offers organisations better insight and fast, effective decision-making capabilities to stay ahead of their industry competitors. In addition to this, it is widely believed that AI will bring about a significant change in automation and autonomous decision making as part of the Fourth Industrial Revolution (Schwab, 2017). Blanco (2018) shows the positive impact AI has on (i) customer service through improved lead times and reliability, (ii) costs through improved productivity, and (iii) cash through improved inventory management. In another example, hardware manufacturer Hitachi initially reduced picking work in a distribution centre by $8 \%$ in an AI trial (Hirayama, Akitomi, Kudo, Miyamoto \& Mine, 2016). These inherent AI benefits allow organisations to focus more on further innovation, drive business growth, and better manage risks and costs (Blanco, 2018).

Exploring the affordances of AI is therefore an important element to this review, especially considering that the definition of AI is very broad (Gurkaynak, Yilmaz \& Haksever, 2016). The review will assist in the understanding of an AI-based service and allow the identification and comparison of these affordances with alternative technology services in the decision-making process (Berger, Denner \& Roeglinger, 2018). This paper will proceed by way of a systematic literature review to identify the affordances of AI that result in business innovation. First, this review will present a systematic review method as proposed by Paré, Tate, Johnstone \& Kitsiou (2016), using specific journals and conference papers. The findings of this review will include definitions and highlight what the literature presents regarding AI affordance of business innovation.

\section{Review Method}

This methodology employs the six generic steps involved in conducting a systematic review, as proposed by Paré, Tate, Johnstone \& Kitsiou (2016). The first step is to define the review plan, followed by a literature search as the second step. Thirdly, papers are selected for appropriateness in the study of AI affordances and business innovation. Fourthly, the quality of the studies is evaluated, followed by the fifth step of data extraction. The final step includes the analysis and synthesis of information with the aim of identifying the affordances for business innovation offered by AI. Gaps in the literature are also identified in this process.

\subsection{Step 1: Review Plan}

As Paré et al. (2016) suggest review planning involves (i) developing a review question, (ii) selecting the type and method of review, and (iii) formulating a review protocol. These are outlined further in this section.

Review Question. This review intends to explain the affordances of AI that result in business innovation in organisations, leading to the following research question: How do artificial intelligence technologies afford business innovation in organisations? The objectives are the following: Identify the

key features of AI; Explain what is considered business innovation; Explain how AI features afford business innovation; Identify the types of business innovation afforded. 
Type and Method of Review. A developmental or theory-building review type (Templier \& Pare, 2015) is adopted as the aim is to develop a typology of affordances for business innovation that arise from AI features. Such an outcome can be described as a descriptive theoretical contribution (Berger et al., 2018).

Review Protocol. The review strategy chosen was more iterative than sequential, thereby allowing the study to start with initial ideas, guided by the research question (Pare et al., 2016). As learning on the topic of AI developed, search strategies were adjusted and searching continued based on this new information. This approach was particularly useful in this review considering the exploratory and explanatory nature of developmental reviews (Rowe, 2014) and because the definitions of AI are very broad (Gurkaynak et al., 2016; Berger et al., 2018; Ertel, 2018).

\subsection{Step 2: Literature Search}

An initial search was carried out, followed by sorting, selecting, acquiring and reading publications (Boell \& Cecez-Kecmanovic, 2014). Through reading, additional terms were identified and searching continued. This iterative process also began to highlight gaps in the literature.

The objective of the initial search was to consolidate a set of recent and relevant publications that help achieve the research objectives. To do so, the top seven journals from the Association for Information Systems (AIS) were searched (Lowry et al., 2013), i.e.: MIS Quarterly, Information Systems Research, Journal of Management Information Systems, Journal of the Association for Information Systems, Information Systems Journal, European Journal of Information Systems, and Journal of Strategic Information Systems. The following leading information systems conferences were also searched: International Conference on Information Systems (ICIS), European Conference on Information Systems (ECIS), Pacific Asia Conference on Information Systems (PACIS), and Americas Conference on Information Systems (AMCIS).

To help to identify the key features of AI and explain how these AI features afford business innovation, the following search string was used to search the title, abstract and keywords: ("artificial intelligence" AND (feature* OR characteristic*)) OR ("artificial intelligence" AND afford*). The search was limited to full-text, peer-reviewed journals and conference papers only, and within a tenyear period (2009 to 2019) as is commonly practiced for systematic reviews (Rowe, 2014). The period of ten years was also selected due to the recent introduction of commercially available AI-powered services; one example being Tesla's autonomous vehicle. Databases such as Ebsco, Web of Science, Taylor \& Francis Online and ScienceDirect were initially trialed for the journal search. The Association for Information Systems (AIS) library was used for the search of conference proceedings.

The results of the initial search across the journals and conference papers yielded a total of 15 articles. This was considered too few and the search was reconducted using the 'broader' search string of "artificial intelligence" in all article's dimensions, as suggested by Bandara et al. (2015) for emerging topics like AI. The journal search produced 95 results, while the conference search produced 978 articles in total. To refine the search, the same search string was limited to the title, abstract and keywords. In addition, the Financial Times Top 50 journals (Ormans, 2016) were also included to cover the scope of management outside of the domain of information systems. AI affordances for business innovation is of direct interest to management, and so it was expected that there would be research on this phenomenon there too. This search resulted in 86 journal articles (Web of Science - all databases) and 153 conference papers. The Journal of Management Information Systems and MIS Quarterly contained 14 and 12 articles respectively, with the remaining articles spread across the remaining 23 journals, indicating that the topic of $\mathrm{AI}$ is still primarily discussed in information systems literature rather than management literature, as shown in figure 1. 


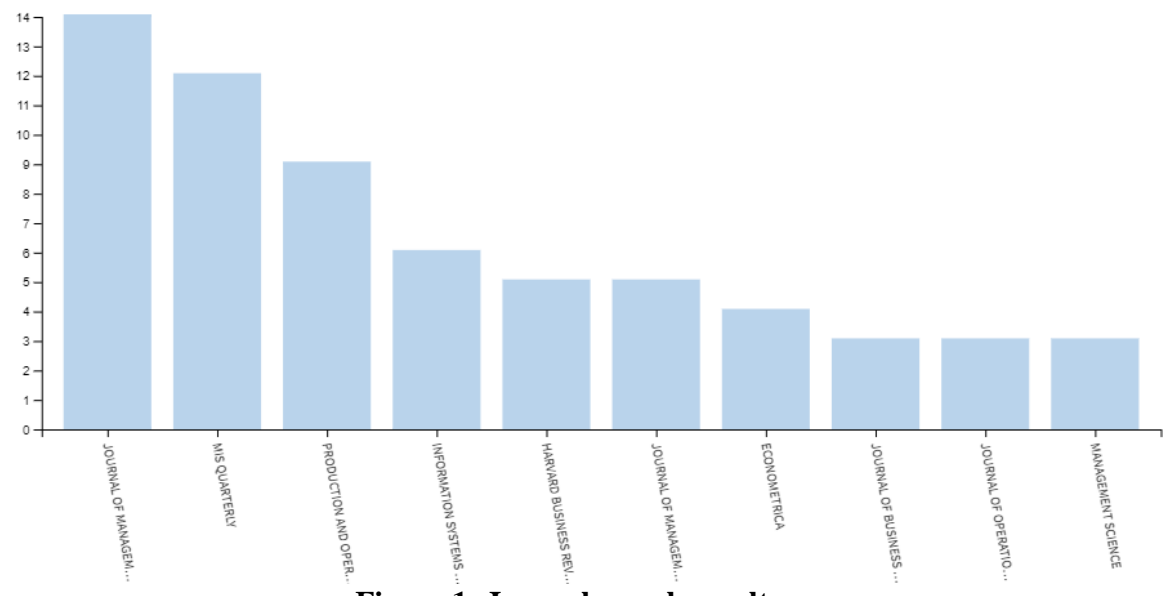

Figure 1: Journal search results 2.

The 153 conference papers were evenly distributed across the four conferences as shown in figure

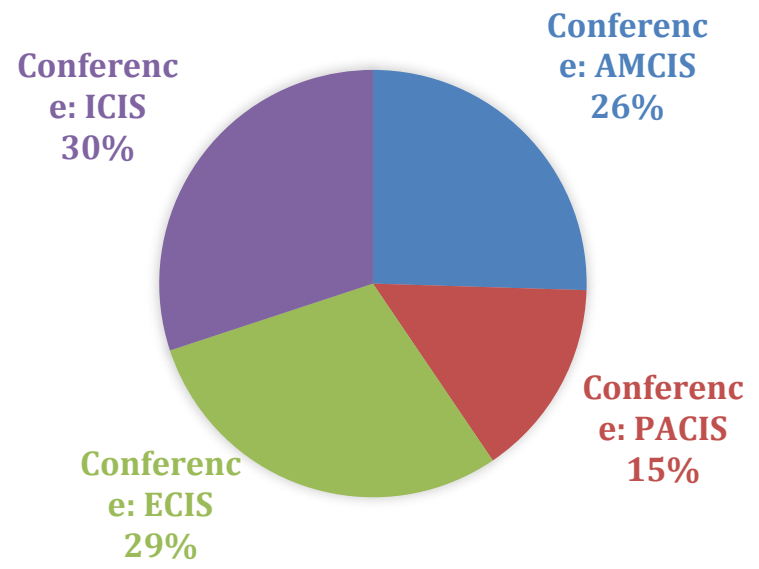

Figure 2: Conference search results

\subsection{Step 3: Selection}

Each of the 86 journal articles and 153 conference papers' titles and abstracts were read. Articles were selected based on whether it was related to or provided information about: (i) Affordances of artificial intelligence, (ii) business innovation where artificial intelligence is involved, (iii) features of artificial intelligence, or (iv) a combination of the first three. Where abstracts were not available, the article introduction was read. Articles not related to these four focal points of the research were excluded from further review. This resulted in a total of 34 articles being included for full text review. Most articles were conference papers.

\subsection{Step 4: Quality}

The full text of the 34 articles were then reviewed. First the introduction and conclusion were read to screen for further relevance and paper credibility (Mikalef et al., 2018). It was found that several 
articles did not address any of the four criteria listed in the selection step. These were thus also excluded from the review, leaving the total at 19 articles (see Appendix A).

\subsection{Step 5: Extraction}

The plan to extract data is based on the core broad topic of artificial intelligence affordances for business innovation, while recognising relevant data in the text related to (i) definitions and key features of AI, (ii) explanations of business innovation, (iii) explanations of affordance in the context of AI, (iv) explanations about how AI or its features afford business innovation, and (v) identification of the types of business innovation afforded by AI.

\subsection{Step 6: Analysis and Synthesis}

The qualitative analysis software application NVivo Pro (version 12) was used to extract and prepare the data for thematic analysis using Braun \& Clarke's (2006) six recursive phases, namely (i) data familiarisation (see step 3 to step 5), (ii) creation of codes (iii) arranging themes from the codes, (iv) reviewing themes for consistency with the data, (v) refining and naming of themes, and (vi) writing the report. The codes were further refined into themes and data analysed within each theme as discussed next.

\section{Findings}

\subsection{Artificial Intelligence Definitions and Capabilities}

Artificial Intelligence is not a new concept. The term was first coined by John McCarthy in 1956. It wasn't until the late nineties when interest and research started to accelerate (Ertel, 2018). The definition of AI varies considerably and is exceptionally broad (Lewis, 1997; Ertel, 2018). No single, consistent and globally accepted definition exists. In fact, it is referred to in several of the articles as a 'black box' (Davenport \& Ronanki, 2018; Leyer \& Schneider, 2019; Pumplun, Tauchert \& Heidt, 2019). Traumer, Oeste-Reiß \& Leimeister $(2017$, p. 3) refer to AI as a "generic term that encompasses a range of approaches and techniques including concepts ... One of these approaches is the concept of ML". The terms artificial intelligence and machine learning are often used interchangeably. For example, Bawack, Wamba \& Carillo (2019, p. 4) note that "most IT companies perceive AI as a term in the computer science field used to describe machines that perform tasks by mimicking human intelligence using abilities acquired through machine learning...". As another example, in Nascimento, da Cunha, de Souza Meirelles, Scornavacca \& de Melo's (2018) literature analysis of research on AI in Management Information Systems, they classify AI into nine subfields and seven techniques as shown in Table 1: 


\begin{tabular}{rlrl}
\hline & \multicolumn{2}{c}{ AI Subfields } & \multicolumn{2}{l}{ AI Techniques } \\
\hline 1. & Expert Systems & 1. & Artificial Neural Networks \\
\hline 2. & General Artificial Intelligence & 2. & Regression based Models \\
\hline 3. & Knowledge based Systems & 3. & Genetic Algorithms \\
\hline 4. & Decision Support & 4. & Fuzzy Logic \\
\hline 5. & Big Data & 5. & Complex Adaptive Systems \\
\hline 6. & Data Mining & 6. & Analytic Hierarchy Process \\
\hline 7. & Predictive Models & 7. & Cluster Analysis \\
\hline 8. & Machine Learning & & \\
\hline 9. & Collaborative Information Systems & & \\
\hline
\end{tabular}

Table 1: AI Subfields and Techniques, source: Nascimento, da Cunha, de Souza Meirelles, Scornavacca \& de Melo (2018)

Bawack et al. (2019) refer to four core AI capabilities: learn, sense, act, and comprehend. Capabilities are reflected in other terms too. Rzepka \& Berger (2018) refer to AI capabilities of learning, reasoning, planning, and reacting to the environment, all of which can be related to the four main capabilities explained by Bawack et al. (2019). In terms of resources, AI requires data sourcing, computing power, storage and skills (Pumplun, Tauchert \& Heidt, 2019; Bawak et al., 2019; Meyer von Wolff, Masuch, Hobert \& Schumann, 2019).

This paper therefore defines AI as a system that makes decisions based on external data (rather than an explicit set of rules) and uses this data to learn about the environment in which it operates and adapts itself to achieve specific [human] goals (Pumplun, Tauchert \& Heidt, 2019). It does so by using one or more of the key four AI capabilities; learn, sense, act, and/or comprehend through a myriad of everemerging mechanisms or technologies like Machine Learning, Robotic Process Automation or Video Analysis as examples (Bawack et al., 2019).

\subsection{AI Affordances and Business Innovation}

The analysis revealed several cases of business innovation and AI affordances of such innovation. Since affordances focus on the business practices as an outcome rather than the properties of the technologies (Fayard \& Weeks, 2014), affordances of AI for business innovation identified in literature included (i) Automate business processes, (ii) Customise end user interaction, (iii) Proactively anticipate and react to changes, (iv) Augment and upskill the workforce, (v) Assist decision making, (vi) Improve risk management, and (vii) Develop and enhance intellectual property. Each affordance is discussed next, with a summary included in Appendix B, Table B1.

Automate business processes - One of the affordances of business innovation in the literature surveyed includes automation of business processes. For example, the automatic updating of customer information such as address changes, or communication updates when an event (such as a lost credit card) is triggered (Daven-port \& Ronanki, 2018).

Customise end user interaction - A customer, supplier or employee (or even process) may often be presented with several options to meet their needs, in order to satisfy the greater business process. Some of the 'noise' or irrelevant information in these options can be filtered out by AI so that the presented options are tailored based on the specific needs of each end user. This results in improved engagement and efficiencies within the business value chain. For example, systems may include health 
treatment recommendations based on an individual's specific health habits, age and medical history (Davenport \& Ronanki, 2018); chatbots are able to "analyze words, phrases and sentence constructions of customers so they can predict customer personality" in order to improve customer service (Nguyen \& Sidorova, 2018, p. 2).

Proactively anticipate and react to changes - A third affordance illustrated by the reviewed literature is the possibility to predict the behaviour of humans, markets, machines and other forces that affect organisations. These include financial time series forecasting, market predictions and fraud detection (Nascimento et al., 2018). Other examples in the literature include the ability to "analyze warranty data to identify safety or quality problems in automobiles and other manufactured products" (Davenport \& Ronanki, 2018, p. 110).

Augment and upskill the workforce - Another affordance for business innovation is by way of addressing human capacity. For example, AI can be used to perform low complexity tasks and free up capacity of the human to focus on more complex tasks that require human intuition or a specific experience requirement (Traumer et al., 2017).

Assist decision making - AI is able to use algorithms and historical information to make suggestions to humans when making business decisions (Rzepka \& Berger, 2018). This affordance would be particularly helpful in the case of an ailing demand forecasting function in the supply chain industries (Mokheseng et al., 2017).

Improve risk management - While several examples have been illustrated in the context of AI affordance through business systems or processes, there is some paucity in AI affordance in the context of information technology (IT) infrastructure. Pike \& Pike (2019) offer an example where AI is used to improve risk management in a highly virtualised IT environment, thereby also maximising availability of crucial business systems. Another example they offer is the adaptive nature of IT security infrastructure by using AI to "analyze the ingested data to ensure that activities on the systems are consistent with the organizations policies, develops compliance reports and sends alerts when activities deviate from expected outcomes" Pike \& Pike (2019, p. 2).

Develop and enhance intellectual property - The generation, storage and access to structured and strategic data is another way in which AI affords business innovation. This can be performed in a variety of ways. One method discussed by Meyer von Wolff et al. (2019) is through chatbots. Chatbots can be used to generate, challenge and store work related knowledge such as software engineering requirements or training material.

\section{Conclusion}

This paper explores how artificial intelligence technologies afford business innovation. By understanding these affordances and the AI features that play a role in it, one can gain a better understanding about the use of AI-enabled technologies and enable one to make better strategic decisions in the interest of the business or future academic research. The paper employs a systematic review of journals and conference papers between 2009 and 2019, and identifies seven key AI affordances for business innovation, namely (i) Automate business processes, (ii) Customise end user interaction, (iii) Proactively anticipate and react to changes, (iv) Augment and upskill the workforce, (v) Assist decision making, (vi) Improve risk management, and (vii) Develop and enhance intellectual property.

The literature surveyed shows that there are several gaps which allow for further research. Firstly, the definition of AI is inconsistent and there is no widely accepted definition. More recent literature has however explored the definitions through techniques, categories and classifications of AI. Secondly, terms such as AI and ML are used interchangeably, despite ML being a sub-set of AI; this presents an opportunity to explore the artifacts of AI and its 'subfields' to distinguish between the two. 
Thirdly, the literature does not sufficiently directly address the topic of AI affordances for business innovation. Instead, most of the literature explains the affordances through inference and focuses on the technology and not the business practices that are afforded. Lastly, the literature has almost always linked AI with another technology or application. Even the resources which AI uses can represent a technology as a dependency or input (e.g. Big Data, Internet, IoT). AI can therefore be considered as a supporting or underlying technology rather than a technology that is directly consumed by a human agent. Further research could explore how these links, techniques and resources are interrelated, related or incorporated into AI.

There are several AI-based technologies and applications being developed (e.g. ML, Deep Learning, Natural Language Processing and Neural Networks) that require the consumer to have a clear understanding of the affordances of such technologies to be able to make informed strategic decisions. Therefore, understanding the affordances of AI in general plays an important role in making such decisions, and this paper begins to address this gap.

\section{References}

Bandara, W., Furtmueller, E., Gorbacheva, E., Miskon, S., \& Beekhuyzen, J. (2015). Achieving rigor in literature reviews: Insights from qualitative data analysis and tool-support. Communications of the Association for Information Systems, 37, 154-204.

Baregheh, A., Rowley, J., \& Sambrook, S. (2009). Towards a multidisciplinary definition of innovation. Management decision, 47(8), 1323-1339.

Bawack, R. E., Wamba, S.F., \& Carillo, K. D. (2019). Artificial Intelligence in Practice: Implications for IS Research. In: Proceedings of the Twenty-fifth Americas Conference on Information Systems (pp. 1-10). Cancun, Mexico.

Berger, S., Denner, M. S., \& Roeglinger, M. (2018). The Nature of Digital TechnologiesDevelopment of a Multi-Layer Taxonomy. In: 26th European Conference on Information Systems (pp. 1-18). Association for Information Systems, Portsmouth, United Kingdom.

Bieringer, A., \& Müller, L. (2018). Integration of Internet of Things technologies in warehouses: A multiple case study on how the Internet of Things technologies can efficiently be used in the warehousing processes. Masters thesis. Jönköping: Jönköping University.

Blanco, A. P. (2018). Artificial intelligence and the consumer packaged goods supply chain. Doctoral dissertation. Cambridge: Massachusetts Institute of Technology.

Boell, S. K., Cecez-Kecmanovic, D. (2018). A Hermeneutic Approach for Conducting Literature Reviews and Literature Searches. Communications of the Association for Information Systems 34(1), 10.

Braun, V., \& Clarke, V. (2006). Using thematic analysis in psychology. Qualitative research in psychology, 3(2), 77-101.

Calatayud, A., Mangan, J., \& Christopher, M. (2019). The self-thinking supply chain. Supply Chain Management: An International Journal, 24(1), 22-38.

Davenport, T. H., \& Ronanki, R. (2018). Artificial intelligence for the real world. Harvard business review, 96(1), 108-116.

Du, W. D., Pan, S. L., Leidner, D. E., \& Ying, W. (2019). Affordances, experimentation and actualization of FinTech: A blockchain implementation study. The Journal of Strategic Information Systems, 28(1), 50-65 (2019).

Ertel, W. (2018). Introduction to artificial intelligence. Cham: Springer.

Fayard, A. L., \& Weeks, J. (2014). Affordances for practice. Information and Organization, 24(4), 236-249. 
Artificial Intelligence Affordances for Business Innovation: A Systematic ... L. Achmat and I. Brown

Fujita, K. (2018). New Approach to Improving Site Operations of Distribution Centers with IoT Technology. Fujitsu Scientific \& Technical Journal, 54(2), 34-38.

Hirayama, J., Akitomi, T., Kudo, F., Miyamoto, A., \& Mine, R. (2016). Case Study of Improving Productivity in Warehouse Work. Hitachi Review, 65(6), 135.

Lewis, H.W. (1997). Fuzzy Control as Artificial Intelligence. In: G. E. Mobus (Ed.), International Federation for Systems Research International Series on Systems Science and Engineering, Vol 10 (pp. 29-58). Springer, Boston, United States of America.

Lehrer, C., Wieneke, A., vom Brocke, J., Jung, R., \& Seidel, S. (2018). How big data analytics enables service innovation: materiality, affordance, and the individualization of service. Journal of Management Information Systems, 35(2), 424-460.

Lowry, B., Moody, D., Gaskin, J., Galletta, F., Humpherys, L., Barlow, B., Wilson, W. (2013). Evaluating Journal Quality and the Association for Information Systems Senior Scholars' Journal Basket via Bibliometric Measures: Do Expert Journal Assessments Add Value? MIS Quarterly, 37(4), 993-1012.

Markus, M. L., \& Silver, M. S. (2008). A foundation for the study of IT effects: A new look at DeSanctis and Poole's concepts of structural features and spirit. Journal of the Association for Information systems, 9(10), 609-632.

Meyer von Wolff, R., Masuch, K., Hobert, S., \& Schumann, M. (2019). What Do You Need Today? An Empirical Systematization of Application Areas for Chatbots at Digital Workplaces. In Proceedings of the Twenty-fifth Americas Conference on Information Systems (AMCIS) (pp. 1-10). Cancun, Mexico.

Mikalef, P., Pappas, O., Krogstie, J., Giannakos, M. (2018). Big Data Analytics Capabilities: A Systematic Literature Review and Research Agenda. Information Systems and e-Business Management, 16(3), 547-578.

Mokheseng, M., Horn, G. S., \& Klopper, A. G. (2017). Supply chain solutions to improve the distribution of antiretroviral drugs (ARVs) to clinics in rural areas: A case study of the QwaQwa district. Health SA Gesondheid, 22(1), 93-104.

Nattrass, N. (2016). Setting minimum wages in South Africa. The Journal of the Helen Suzman Foundation, 1(78), 32-43.

Nguyen, Q. N., \& Sidorova, A. (2018). Understanding user interactions with a chatbot: a selfdetermination theory approach. In Proceedings of the Twenty-fourth Americas Conference on Information Systems (AMCIS2018) (pp. 1-5). New Orleans, United States of America.

Ntsabo, M. (2019). Understanding the Fourth Industrial Revolution in a South African Context. Retrieved July 16, 2019, from https://ewn.co.za/2019/03/15/understanding-the-fourth-industrialrevolution-in-a-south-african-context

Ormans, L. (2016). 50 Journals used in FT Research Rank. Financial Times. Retrieved July 12, 2019, from https://www.ft.com/content/3405a512-5cbb-11e1-8f1f-00144feabdc0

Paré, G., Tate, M., Johnstone, D., \& Kitsiou, S. (2016). Contextualizing the twin concepts of systematicity and transparency in information systems literature reviews. European Journal of Information Systems, 25(6), 493-508.

Pike, N., \& Pike, R. (2019). Progressing from the SOC to the EOC. In Proceedings of the Twentyfifth Americas Conference on Information Systems (AMCIS) (pp. 1-5). Cancun, Mexico.

Plastino, E., \& Purdy, M. (2018). Game changing value from artificial intelligence: eight strategies. Strategy \& Leadership, 46(1), 16-22.

Pumplun, L., Tauchert, C., \& Heidt, M. (2019). A New Organizational Chassis for Artificial Intelligence-Exploring Organizational Readiness Factors. In Proceedings of the Twenty-Seventh European Conference on Information Systems (ECIS2019) (pp. 1-15). Darmstadt Technical University, Department of Business Administration, Economics and Law, Institute for Business Studies (BWL), Stockholm-Uppsala, Sweden.

Rowe, F. (2014). What literature review is not: diversity, boundaries and recommendations. European Journal of Information Systems, 23(3), 241-255. 
Artificial Intelligence Affordances for Business Innovation: A Systematic ... L. Achmat and I. Brown

Rzepka, C., \& Berger, B. (2018). User interaction with AI-enabled systems: a systematic review of IS research. In Proceedings of the Thirty Ninth International Conference on Information Systems (ICIS2018) (pp. 1-17). San Francisco, United States of America.

Salam, M. A., \& Khan, S. A. (2018). Achieving supply chain excellence through supplier management: a case study of fast moving consumer goods. Benchmarking: An International Journal, 25(9), 4084-4102.

Schwab, K. (2017). The fourth industrial revolution. Penguin, London.

Sun, Z. (2018). Innovation and Entrepreneurship in the 4th Industrial Revolution. Joint Workshop on Entrepreneurship. PNG University of Technology, 1-34.

Templier, M., \& Paré, G. (2015). A Framework for Guiding and Evaluating Literature Reviews. Communications of the Association for Information Systems, 37(6), 112-137.

Traumer, F., Oeste-Reiß, S., \& Leimeister, J. M. (2017). Towards a future reallocation of work between humans and machines-taxonomy of tasks and interaction types in the context of machine learning. In Proceedings of the Thirty Eighth International Conference on Information Systems (ICIS2017) (pp. 1-11). South Korea.

Zhou, H. (2016). Application Analysis on Internet of Things Technology in the Logistics System. In 2016 4th International Conference on Electrical \& Electronics Engineering and Computer Science (ICEEECS 2016). Atlantis Press, Jinan, China.

\section{APPENDIX A: Final 19 Papers Identified}

1. Ahmadian, M., \& Lee, O. K. D. (2017). AI-based voice assistant systems: Evaluating from the interaction and trust perspectives. In Proceedings of the Twenty-third Americas Conference on Information Systems (AMCIS) (pp. 1-10). Boston, United States of America.

2. Bawack, R. E., Wamba, S.F., \& Carillo, K. D. (2019). Artificial Intelligence in Practice: Implications for IS Research. In Proceedings of the Twenty-fifth Americas Conference on Information Systems (AMCIS) (pp. 1-10). Cancun, Mexico.

3. Davenport, T. H., \& Ronanki, R. (2018). Artificial intelligence for the real world. Harvard Business Review, 96(1), 108-116.

4. Dellermann, D., Lipusch, N., Ebel, P., Popp, K. M., \& Leimeister, J. M. (2017). Finding the unicorn: Predicting early stage startup success through a hybrid intelligence method. In Proceedings of the Thirty Eighth International Conference on Information Systems (ICIS) (pp. 1-12). South Korea.

5. Dias, M., Pan, S., \& Tim, Y. (2019). Knowledge Embodiment of Human and Machine Interactions: Robotic-Process-Automation at the Finland Government. In Proceedings of the Twenty-Seventh European Conference on Information Systems (ECIS) (pp. 1-11), StockholmUppsala, Sweden.

6. Harfouche, A., Quinio, B., Skandrani, S., \& Marciniak, R. (2017). A framework for artificial knowledge creation in organizations. In Proceedings of the Thirty Eighth International Conference on Information Systems (ICIS) (pp. 1-11). Seoul, South Korea.

7. Leyer, M., Schneider, S. (2019). Me, You or AI? How do we feel about delegation. In Proceedings of the Twenty-Seventh European Conference on Information Systems (ECIS) (pp. 1-17). Stockholm-Uppsala, Sweden. 
Artificial Intelligence Affordances for Business Innovation: A Systematic ... L. Achmat and I. Brown

8. Mesbah, N., Tauchert, C., Olt, C. M., \& Buxmann, P. (2019). Promoting Trust in AI-based Expert Systems. In Proceedings of the Twenty-Fifth Americas Conference on Information Systems (AMCIS) (pp. 1-10). Cancun, Mexico.

9. Meyer von Wolff, R., Masuch, K., Hobert, S., \& Schumann, M. (2019). What Do You Need Today?-An Empirical Systematization of Application Areas for Chatbots at Digital Workplaces. In Proceedings of the Twenty-fifth Americas Conference on Information Systems (AMCIS) (pp. 1-10). Cancun, Mexico.

10. Nagar, Y., \& Malone, T. (2011). Making business predictions by combining human and machine intelligence in prediction markets. Association for Information Systems. In Proceedings of the Thirty-Second International Conference on Information Systems (ICIS) (pp. 1-16). Shanghai, China.

11. Nascimento, A. M., da Cunha, M. A. V. C., de Souza Meirelles, F., Scornavacca, E., \& de Melo, V. V. (2018). A Literature Analysis of Research on Artificial Intelligence in Management Information System (MIS). In Proceedings of the Twenty-fourth Americas Conference on Information Systems (AMCIS) (pp. 1-10). New Orleans, United States of America.

12. Nguyen, Q. N., \& Sidorova, A. (2017). AI capabilities and user experiences: a comparative study of user reviews for assistant and non-assistant mobile apps. In Proceedings of the Twenty-Third Americas Conference on Information Systems (AMCIS) (pp. 1-10). Boston, United States of America.

13. Nguyen, Q. N., \& Sidorova, A. (2018). Understanding user interactions with a chatbot: a selfdetermination theory approach. In Proceedings of the Twenty-fourth Americas Conference on Information Systems (AMCIS) (pp. 1-5). New Orleans, United States of America.

14. Pike, N., \& Pike, R. (2019). Progressing from the SOC to the EOC. In Proceedings of the Twenty-fifth Americas Conference on Information Systems (AMCIS) (pp. 1-5). Cancun, Mexico.

15. Pumplun, L., Tauchert, C., \& Heidt, M. (2019). A New Organizational Chassis for Artificial Intelligence-Exploring Organizational Readiness Factors. In Proceedings of the TwentySeventh European Conference on Information Systems (ECIS) (pp. 1-15). Stockholm-Uppsala, Sweden.

16. Rzepka, C., \& Berger, B. (2018). User interaction with AI-enabled systems: a systematic review of IS research. In Proceedings of the Thirty Ninth International Conference on Information Systems (ICIS) (pp. 1-17). San Francisco, United States of America.

17. Strohmann, T., Fischer, S., Siemon, D., Brachten, F., Lattemann, C., Robra-Bissantz, S., \& Stieglitz, S. (2018). Virtual Moderation Assistance: Creating Design Guidelines for Virtual Assistants Supporting Creative Workshops. In Proceedings of the Twenty-Second Pacific Asia Conference on Information Systems (PACIS) (pp. 1-14). Japan.

18. Traumer, F., Oeste-Reiß, S., \& Leimeister, J. M. (2017). Towards a future reallocation of work between humans and machines-taxonomy of tasks and interaction types in the context of machine learning. In Proceedings of the Thirty Eighth International Conference on Information Systems (ICIS) (pp. 1-11). South Korea. 
Artificial Intelligence Affordances for Business Innovation: A Systematic ... L. Achmat and I. Brown

19. Wuenderlich, N. V., \& Paluch, S. (2017). A nice and friendly chat with a bot: User perceptions of AI-based service agents. In Proceedings of the Thirty Eighth International Conference on Information Systems (ICIS) (pp. 1-11). Seoul, South Korea.

\section{APPENDIX B: References Supporting Each Affordance}

Table B1 References Supporting Each of the Seven Affordances

\begin{tabular}{|c|l|}
\hline Affordance & Reference (From Appendix A) \\
\hline Automate business processes & {$[3,5,9,12,19]$} \\
\hline Customise end user interaction & {$[3,912,17,19]$} \\
\hline Proactively anticipate and react to changes & {$[3,4,10,11]$} \\
\hline Augment and upskill the workforce & {$[3,9,11,18]$} \\
\hline Assist decision making & {$[3,4,7,8,11,16]$} \\
\hline Improve risk management & {$[3,11,14]$} \\
\hline Develop and enhance intellectual property & {$[3,6,9,11,18]$} \\
\hline
\end{tabular}

